OPEN ACCESS

Edited by:

Gen-Min Lin,

Hualien Armed Forces Genera Hospital, Taiwan

Reviewed by:

Jun Lyu,

First Affiliated Hospital of Jinan University, China

Sukrit Kanchanasurakit,

University of Phayao, Thailand

*Correspondence:

Zhi-jian Hu

huzhiijan@fjmu.edu.cn

Feng Yang

yf5067505@163.com

tThese authors have contributed equally to this work

Specialty section:

This article was submitted to Cardiovascular Epidemiology and

Prevention,

a section of the journa Frontiers in Cardiovascular Medicine

Received: 31 July 2021 Accepted: 11 October 2021 Published: 03 November 2021

Citation:

Liu Z-q, Huang Z-w, Kang S-I, Hu C-C, Chen F, He F, Lin Z, Yang F and Hu Z-j

(2021) Serum Uric Acid and Cardiovascular or All-Cause Mortality in Peritoneal Dialysis Patients: $A$

Systematic Review and Meta-Analysis. Front. Cardiovasc. Med. 8:751182. doi: 10.3389/fcvm.2021.751182

\section{Serum Uric Acid and Cardiovascular or All-Cause Mortality in Peritoneal Dialysis Patients: A Systematic Review and Meta-Analysis}

\author{
Zhi-qiang Liu ${ }^{1 \dagger}$, Zhi-wen Huang ${ }^{1 \dagger}$, Shu-ling Kang ${ }^{2,3+}$, Chan-chan Hu ${ }^{1}$, Fa Chen ${ }^{1}$, Fei He ${ }^{1}$, \\ Zheng Lin ${ }^{1}$, Feng Yang ${ }^{4 *}$ and Zhi-jian $\mathrm{Hu}^{1 *}$ \\ ${ }^{1}$ Department of Epidemiology and Health Statistics, School of Public Health, Fujian Medical University, Fuzhou, China, \\ ${ }^{2}$ Fuzhou Center for Disease Control and Prevention, Fuzhou, China, ${ }^{3}$ Department of Preventive Medicine, School of Public \\ Health, Fujian Medical University, Fuzhou, China, ${ }^{4}$ Department of Nephrology, Affiliated Fuzhou First Hospital of Fujian \\ Medical University, Fuzhou, China
}

Background: Studies have shown inconsistent associations between serum uric acid (SUA) levels and mortality in peritoneal dialysis (PD) patients. We conducted this meta-analysis to determine whether SUA levels were associated with cardiovascular or all-cause mortality in PD patients.

Methods: PubMed, Embase, Web of Science, the Cochrane Library, CNKI, VIP, Wanfang Database, and trial registry databases were systematically searched up to April 11, 2021. Cohort studies of SUA levels and cardiovascular or all-cause mortality in PD patients were obtained. Random effect models were used to calculate the pooled adjusted hazard ratio $(H R)$ and corresponding 95\% confidence interval (Cl). Sensitivity analyses were conducted to assess the robustness of the pooled results. Subgroup analyses and meta-regression analyses were performed to explore the sources of heterogeneity. Funnel plots, Begg's tests, and Egger's tests were conducted to evaluate potential publication bias. The GRADE approach was used to rate the certainty of evidence. This study was registered with PROSPERO, CRD42021268739.

Results: Seven studies covering 18,113 PD patients were included. Compared with the middle SUA levels, high SUA levels increased the risk of all-cause mortality $(H R=1.74$, 95\% Cl: $1.26-2.40, R^{2}=34.8 \%, \tau^{2}=0.03$ ), low SUA levels were not statistically significant with the risk of all-cause or cardiovascular mortality $(H R=1.04,95 \% \mathrm{Cl}$ : $0.84-1.29, I^{2}=43.8 \%, \tau^{2}=0.03 ; H R=0.89,95 \% C l: 0.65-1.23, I^{2}=36.3 \%, \tau^{2}=0.04$; respectively). Compared with the low SUA levels, high SUA levels were not statistically associated with an increased risk of all-cause or cardiovascular mortality $(H R=1.19$, 95\%Cl: 0.59-2.40, $I^{2}=88.2 \%, \tau^{2}=0.44 ; H R=1.22,95 \% \mathrm{Cl}: 0.39-3.85, l^{2}=89.3 \%$, $\tau^{2}=0.92$; respectively).

Conclusion: Compared with middle SUA levels, high SUA levels are associated with an increased risk of all-cause mortality in PD patients. SUA levels may not be associated with cardiovascular mortality. More high-level studies, especially randomized controlled 
trials, are needed to determine the association between SUA levels and cardiovascular or all-cause mortality in PD patients.

Systematic Review Registration: https://www.crd.york.ac.uk/prospero/display_ record.php?ID=CRD42021268739, identifier: CRD42021268739.

Keywords: serum uric acid, cardiovascular mortality, all-cause mortality, peritoneal dialysis, meta-analysis

\section{INTRODUCTION}

Chronic kidney disease (CKD) has become one of the most critical public health problems globally. The global prevalence of CKD is estimated at $13.4 \%$, which is likely to rise further as the population ages and diabetes increases (1). In 2017, about 1.2 million people died of CKD worldwide, with a $41.5 \%$ increase in global mortality between 1990 and 2017 (2). End-stage renal disease (ESRD) is a critical aspect of the severe burden of
CKD. The treatment of ESRD includes supportive care and renal replacement therapy, including hemodialysis (HD), peritoneal dialysis (PD), and renal transplantation (3). Liyanage et al. (4) reported ESRD renal replacement therapy data in 123 countries or regions, and the results showed that about 2.62 million patients received renal replacement therapy in 2010, including about 2.05 million dialysis patients. In the world, PD is not as extensive as HD. In a survey of 125 countries, PD and HD can be implemented in 95 (76\%) and 119 (95\%) countries, respectively

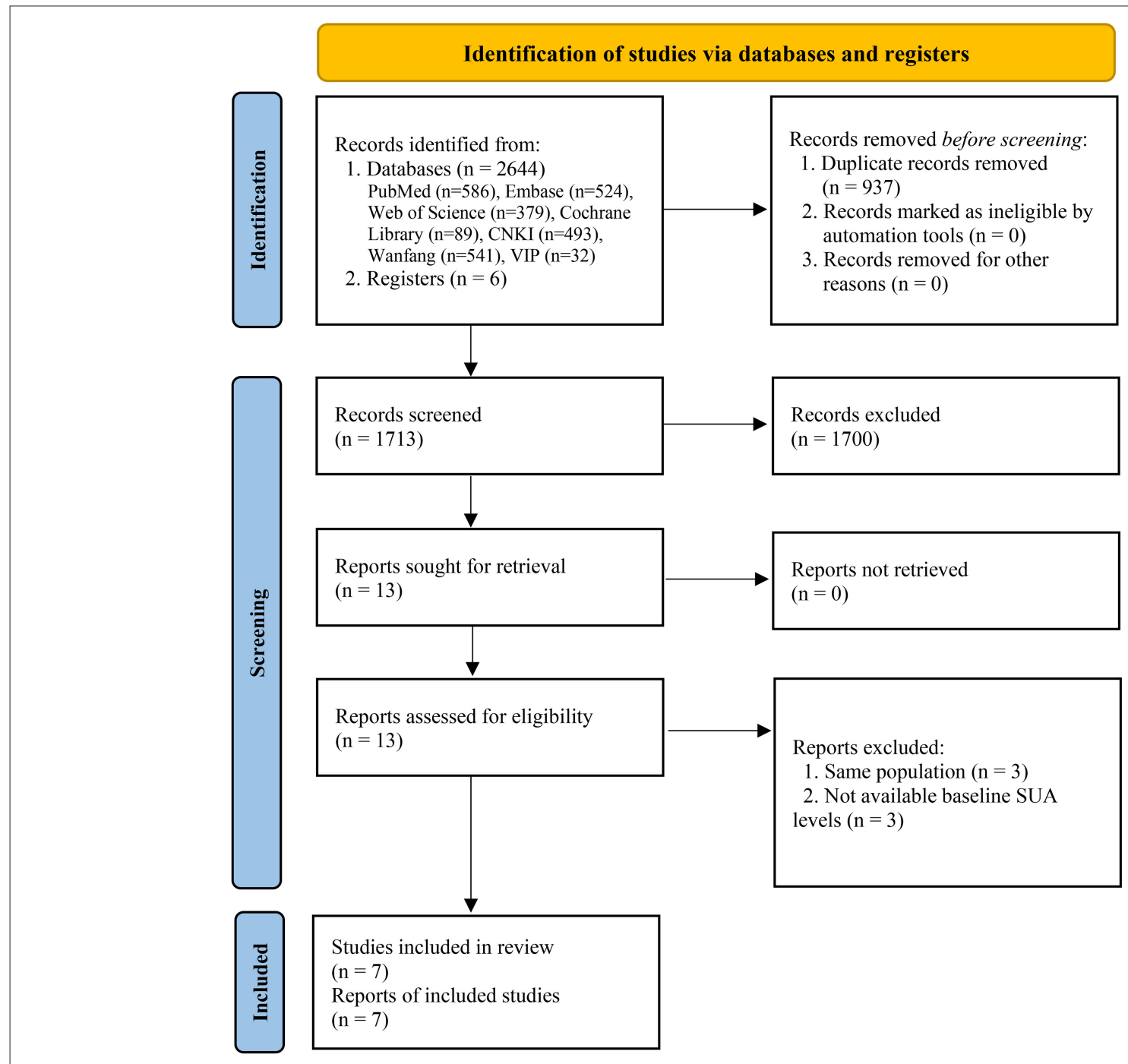

FIGURE 1 | Flow diagram of systematic literature search. 
TABLE 1 | Characteristics of 7 studies included in the meta-analysis.

\begin{tabular}{|c|c|c|c|c|c|c|c|c|c|c|c|c|c|}
\hline Author & Country & $\begin{array}{l}\text { Patients } \\
\text { (n) }\end{array}$ & $\begin{array}{c}\text { Age } \\
\text { (years) }\end{array}$ & $\begin{array}{l}\text { Male } \\
(\%)\end{array}$ & $\begin{array}{l}\text { Hypertension } \\
\text { (\%) }\end{array}$ & $\begin{array}{l}\text { Diabetes } \\
(\%)\end{array}$ & $\begin{array}{l}\text { Baseline } \\
\text { uric acid } \\
\text { (mg/dL) }\end{array}$ & $\begin{array}{l}\text { Follow-up } \\
\text { (months) }\end{array}$ & $\begin{array}{l}\text { All-cause } \\
\text { death } \\
(n)\end{array}$ & $\begin{array}{l}\text { CV } \\
\text { death } \\
(n)\end{array}$ & $\begin{array}{l}\text { Comparison } \\
\text { (mg/dL) }\end{array}$ & $\begin{array}{l}\text { Adjusted } H R \\
(95 \% \mathrm{Cl})\end{array}$ & Adjustments \\
\hline \multirow[t]{2}{*}{$\begin{array}{l}\text { Feng et al. } \\
\text { (20) }\end{array}$} & \multirow[t]{2}{*}{ China } & \multirow[t]{2}{*}{156} & \multirow[t]{2}{*}{$54.1 \pm 17.4$} & \multirow[t]{2}{*}{63.0} & \multirow[t]{2}{*}{92.0} & \multirow[t]{2}{*}{25.0} & \multirow[t]{2}{*}{$8.50 \pm 2.10$} & \multirow[t]{2}{*}{$31.3 \pm 17.5$} & \multirow[t]{2}{*}{41} & \multirow[t]{2}{*}{ NA } & $\begin{array}{l}\text { Low vs. Middle } \\
\leq 7.0 \text { vs. } 7.0-10.0\end{array}$ & $\begin{array}{l}1.15(0.20-6.61) \\
\text { All-cause mortality }\end{array}$ & \multirow{2}{*}{$\begin{array}{l}\text { Age, albumin, DM, } \\
\text { hypertensive nephropathy, } \\
\text { RRF. }\end{array}$} \\
\hline & & & & & & & & & & & $\begin{array}{l}\text { High vs. Middle } \\
\geq 10.0 \text { vs. } 7.0-10.0\end{array}$ & $\begin{array}{l}2.96(1.29-6.79) \\
\text { All-cause mortality }\end{array}$ & \\
\hline \multirow[t]{2}{*}{$\begin{array}{l}\text { Dong et al. } \\
\text { (31) }\end{array}$} & \multirow[t]{2}{*}{ China } & \multirow[t]{2}{*}{2,193} & \multirow[t]{2}{*}{$58.1 \pm 15.5$} & \multirow[t]{2}{*}{49.1} & \multirow[t]{2}{*}{ NA } & \multirow[t]{2}{*}{37.9} & \multirow[t]{2}{*}{$6.41 \pm 1.87$} & \multirow[t]{2}{*}{ Median 26.5} & \multirow[t]{2}{*}{586} & \multirow[t]{2}{*}{231} & $\begin{array}{l}\text { Low vs. Middle } \\
\text { M: } 2.09-5.79 \text { vs. } \\
5.80-7.38 \\
\text { FM: } 1.74-5.37 \text { vs. } \\
5.38-6.65\end{array}$ & $\begin{array}{l}0.81 \text { (0.59-1.11) } \\
\text { All-cause mortality } \\
0.78(0.45-1.35) \\
\text { CV mortality }\end{array}$ & \multirow[t]{2}{*}{$\begin{array}{l}\text { Age, RRF, serum albumin, } \\
\text { hemoglobin, phosphate, } \\
\text { CRP, the history of CVD, } \\
\text { diabetes, BMl, mean arterial } \\
\text { pressure, LDLC, center size, } \\
\text { gender. }\end{array}$} \\
\hline & & & & & & & & & & & $\begin{array}{l}\text { High vs. Low } \\
\text { M: } 7.39-16.7 \text { vs. } \\
2.09-5.79 \\
\text { FM: } 6.66-8.08 \text { vs. } \\
1.74-5.37\end{array}$ & $\begin{array}{l}1.21 \text { ( } 0.85-1.72) \\
\text { All-cause mortality } \\
1.35(0.74-2.46) \\
\text { CV mortality }\end{array}$ & \\
\hline \multirow[t]{2}{*}{ Xia et al. (23) } & \multirow[t]{2}{*}{ China } & \multirow[t]{2}{*}{985} & \multirow[t]{2}{*}{$48.3 \pm 15.4$} & \multirow[t]{2}{*}{58.4} & \multirow[t]{2}{*}{65.7} & \multirow[t]{2}{*}{23.0} & \multirow[t]{2}{*}{$7.00 \pm 1.30$} & \multirow[t]{2}{*}{ Median 25.3} & \multirow[t]{2}{*}{144} & \multirow[t]{2}{*}{64} & $\begin{array}{l}\text { Low vs. Middle } \\
\text { M: }<6.67 \text { vs. } \\
6.67-7.56 \\
\text { FM: }<6.19 \text { vs. } \\
6.19-7.13\end{array}$ & $\begin{array}{l}0.78 \text { (0.50-1.22) } \\
\text { All-cause mortality } \\
0.51(0.25-1.04) \\
\text { CV mortality }\end{array}$ & $\begin{array}{l}\text { Age, BMI, Davies } \\
\text { comorbidity score, } \\
\text { hemoglobin, serum albumin, } \\
\text { serum creatinine, } \\
\text { albumin-corrected calcium, } \\
\text { serum phosphorus, total } \\
\text { triglyceride, }\end{array}$ \\
\hline & & & & & & & & & & & $\begin{array}{l}\text { High vs. Low } \\
\text { M: } 7.56 \text { vs. }<6.67 \\
\text { FM: }>7.13 \text { vs. } \\
<6.19\end{array}$ & $\begin{array}{l}1.93 \text { ( } 1.27-2.93) \\
\text { All-cause mortality } \\
3.31(1.70-6.44) \\
\text { CV mortality }\end{array}$ & $\begin{array}{l}\text { LDLC, residual kidney } \\
\text { function, log-transformed } \\
\text { high-sensitivity } C \text {-creative } \\
\text { protein level, total Kt } N \text {, use } \\
\text { of allopurinol, loop diuretics, } \\
\text { angiotensin-converting } \\
\text { enzyme inhibitor, or } \\
\text { angiotensin receptor } \\
\text { blocker. }\end{array}$ \\
\hline Lai et al. (21) & China & 492 & $53.5 \pm 15.3$ & 48.0 & 85.2 & 34.6 & $\begin{array}{l}7.20(\mathrm{IQR} \\
6.30-8.20)\end{array}$ & Median 36.4 & 127 & 74 & $\begin{array}{l}\text { Low vs. Middle } \\
\text { M: } \leq 6.8 \text { vs. } 6.9-8.0 \\
\text { FM: } \leq 6.5 \text { vs. } \\
6.6-7.6\end{array}$ & $\begin{array}{l}0.94 \text { (0.63-1.40) } \\
\text { All-cause mortality } \\
0.96(0.56-1.65) \\
\text { CV mortality }\end{array}$ & $\begin{array}{l}\text { Age, sex, BMl, the } \\
\text { pre-dialysis status, smoking } \\
\text { status, medications (ACE } \\
\text { inhibitor/ARB, erythropoiesis } \\
\text { stimulating agents, } \\
\text { furosemide, vitamin D, } \\
\text { statin, allopurinol, }\end{array}$ \\
\hline
\end{tabular}


TABLE 1 | Continued

\begin{tabular}{|c|c|c|c|c|c|c|c|c|c|c|c|c|c|}
\hline Author & Country & $\begin{array}{l}\text { Patients } \\
\text { (n) }\end{array}$ & $\begin{array}{c}\text { Age } \\
\text { (years) }\end{array}$ & $\begin{array}{l}\text { Male } \\
(\%)\end{array}$ & $\begin{array}{l}\text { Hypertension } \\
\text { (\%) }\end{array}$ & $\begin{array}{c}\text { Diabetes } \\
(\%)\end{array}$ & $\begin{array}{l}\text { Baseline } \\
\text { uric acid } \\
\text { (mg/dL) }\end{array}$ & $\begin{array}{l}\text { Follow-up } \\
\text { (months) }\end{array}$ & $\begin{array}{l}\text { All-cause } \\
\text { death } \\
\text { (n) }\end{array}$ & $\begin{array}{l}\text { CV } \\
\text { death } \\
(n)\end{array}$ & $\begin{array}{l}\text { Comparison } \\
\text { (mg/dL) }\end{array}$ & $\begin{array}{l}\text { Adjusted } H R \\
(95 \% \mathrm{Cl})\end{array}$ & Adjustments \\
\hline & & & & & & & & & & & $\begin{array}{l}\text { High vs. Low } \\
\text { M: } \geq 8.1 \text { vs. } \leq 6.8 \\
\text { FM: } \geq 7.7 \text { vs. } \leq 6.5\end{array}$ & $\begin{array}{l}0.40(0.24-0.67) \\
\text { All-cause mortality } \\
0.40(0.20-0.80) \\
\text { CV mortality }\end{array}$ & $\begin{array}{l}\text { Calcium channel blocker); } \\
\text { comorbidities (DM, } \\
\text { hypertension, CVD, } \\
\text { Charlson score); PD-related } \\
\text { parameters (weekly total } \\
\text { Kt } / \mathrm{V} \text { urea, nPNA, } \\
\text { dialysate-to-plasma (D/P) } \\
\text { creatinine at } 4 \mathrm{~h} \text {, } \\
\text { ultrafiltration, 24-h urine } \\
\text { output, RRF), laboratory } \\
\text { data (BUN, creatinine, } \\
\text { albumin, GPT, WBC counts, } \\
\text { alkaline phosphate, } \\
\text { hemoglobin, ferritin, } \\
\text { transferrin saturation, } \\
\text { cholesterol, triglyceride, } \\
\text { PTH, calcium, phosphate). }\end{array}$ \\
\hline $\begin{array}{l}\text { Xiang et al. } \\
(24)\end{array}$ & China & 9,405 & $52.5 \pm 14.6$ & 54.9 & NA & 12.2 & $7.07 \pm 1.25$ & Median 29.4 & 1,226 & 515 & $\begin{array}{l}\text { High vs. Middle } \\
\geq 8.04 \text { vs. } 6.68-7.27\end{array}$ & $\begin{array}{l}1.16 \text { (0.95-1.43) } \\
\text { All-cause mortality } \\
1.17(0.82-1.66) \\
\text { CV mortality } \\
\\
1.48(1.19-1.85) \\
\text { All-cause mortality }\end{array}$ & $\begin{array}{l}\text { Age, sex, BMI, DM, CVD, } \\
\text { RRF, hemoglobin, serum } \\
\text { albumin, serum potassium, } \\
\text { serum natrium, serum } \\
\text { phosphorus, serum } \\
\text { calcium, serum parathyroid } \\
\text { hormone, serum creatinine, } \\
\text { and fasting plasma glucose. }\end{array}$ \\
\hline Qiu et al. (32) & China & 140 & $\begin{array}{c}57.0 \\
(44.0 \sim 65.0)\end{array}$ & 45.0 & 94.3 & 37.9 & $7.57 \pm 2.46$ & Median 31.9 & 48 & NA & $\begin{array}{l}\text { Low vs. Middle } \\
<6.51 \text { vs. } 6.52-8.73 \\
\text { High vs. Low } \geq 8.73 \\
\text { vs. }<6.51\end{array}$ & $\begin{array}{l}1.04(0.46-2.36) \\
\text { All-cause mortality } \\
2.31(1.06-5.02) \\
\text { All-cause mortality }\end{array}$ & $\begin{array}{l}\text { Age, DM, hypertension, } \\
\text { CVD, kalium, RRF, uric acid } \\
\text { reduction medicine, } \\
\text { diuretics, ESA, BMI. }\end{array}$ \\
\hline $\begin{array}{l}\text { Sugano et al. } \\
\text { (22) }\end{array}$ & Japan & 4,742 & $63.0 \pm 14.0$ & 61.5 & NA & 29.1 & $6.49 \pm 1.40$ & Median 28.0 & 379 & 129 & $\begin{array}{l}\text { Low vs. Middle } \\
<5.0 \text { vs. } 7.0-7.5 \\
\text { High vs. Middle } \\
>8.5 \text { vs. } 7.0-7.5\end{array}$ & $\begin{array}{l}1.80(1.13-2.87) \\
\text { All-cause mortality } \\
1.93(1.15-3.24) \\
\text { All-cause mortality }\end{array}$ & $\begin{array}{l}\text { Age, sex, dialysis duration, } \\
\text { BMI, UV, underlying disease, } \\
\text { comorbid disease, } \\
\text { medication and laboratory } \\
\text { data. }\end{array}$ \\
\hline
\end{tabular}

Conversion factors for units: to convert uric acid in $\mathrm{mg} / \mathrm{dL}$ to $\mu \mathrm{mo} / \mathrm{L}$, multiply by 59.48 .

The group behind vs. is the reference group.

HR, hazard ratio; Cl, confidence interval; M, male; FM, female; CRP, C-creative protein; BMI, body mass index; CV, cardiovascular; CVD, cardiovascular disease; DM, diabetes mellitus; LDLC, Iow-density lipoprotein cholesterol; NA, not available; IQR, interquartile range; PD, peritoneal dialysis; UV, urinary volume; RRF, residual renal function; ACE, angiotensin-converting enzyme; ARB, angiotensin II receptor blocker; nPNA, normalized protein nitrogen appearance; BUN, blood urea nitrogen; GPT, glutamic-pyruvic transaminase; WBC, white blood cell; PTH, intact parathyroid hormone; ESA, erythropoiesis stimulating agents. 
(5). However, compared with $\mathrm{HD}, \mathrm{PD}$ has characteristics of the lower cost, the convenience of home therapy, and a flexible schedule (6). Recent studies have consistently shown that PD patients have higher early survival than HD patients (7-9).

Uric acid is the ultimate oxidation product of purine catabolism in humans, including exogenous and endogenous purine metabolism $(10,11)$. Hyperuricemia is one of the risk factors for kidney disease, diabetes, and hypertension $(12,13)$. High uric acid levels can also lead to increased all-cause mortality of obesity (14) and chronic heart failure (15). Two-thirds of uric acid is excreted in the urine (16). Uric acid levels are often elevated in patients with $\mathrm{CKD}$ due to decreased renal function. Meta-analyses of CKD patients have shown a U-shaped trend between SUA and all-cause mortality (17), and higher SUA levels are significantly associated with increased risk of cardiovascular mortality (18). Another meta-analysis of HD patients has shown that high SUA levels are a protective factor for cardiovascular mortality (19). However, there is no meta-analysis about the association between SUA levels and mortality in PD patients.

The association between SUA levels and all-cause mortality in PD patients is inconsistent. Feng et al. (20) found that high SUA was associated with increased all-cause mortality; Lai et al. (21) found that high SUA was associated with low risk of all-cause mortality; while Sugano et al. (22) found a Ushaped relationship between SUA levels and all-cause mortality. Similarly, the association between SUA levels and cardiovascular mortality in PD patients is controversial. Lai et al. (21) found that high SUA levels were associated with low risk of cardiovascular mortality; Xia et al. (23) found that the higher the SUA levels, the higher the cardiovascular mortality; while Xiang et al. (24) found that there was no significant relationship between SUA levels and cardiovascular mortality. Therefore, we performed a systematic review and meta-analysis to summarize the relevant studies and clarify the association between SUA levels and cardiovascular or all-cause mortality in PD patients. The objective of the metaanalysis can be described in the form of a PI(E)CO statement as follows: in peritoneal dialysis patients (population), how do different baseline serum uric acid levels (low vs. middle, high vs. middle, high vs. low) (exposure vs. comparator) influence the cardiovascular or all-cause mortality (outcomes)?

\section{MATERIALS AND METHODS}

This study was conducted following the Preferred Reporting Items for Systematic reviews and Meta-Analyses (PRISMA) statement (25). The protocol was registered at PROSPERO (CRD42021268739, https://www.crd.york.ac.uk/prospero/ display_record.php?ID=CRD42021268739).

\section{Literature Search}

We systematically searched PubMed, Embase, Web of Science, the Cochrane Library, Chinese National Knowledge Infrastructure (CNKI), Chinese Scientific Journal Database (VIP), and Wanfang Database to identify relevant studies up to April 11, 2021. We used the following search strategies to retrieve articles: ("uric acid" OR hyperuricemia OR urate) AND (peritoneal dialysis OR dialysis) AND (mortality OR death OR survival OR prognosis OR outcome OR cardiovascular disease OR cardiovascular events OR stroke). Besides, we searched the clinical trial registries (https://www.clinicaltrials.gov/) using the keywords of "uric acid" and "peritoneal dialysis" to identify the relevant unpublished studies. We also manually checked the reference lists of retrieved studies to identify potentially missing relevant studies.

\section{Inclusion and Exclusion Criteria}

Inclusion criteria: (1) cohort study design; (2) patients with chronic kidney disease receiving peritoneal dialysis (which uses the peritoneum as a dialysis membrane by means of dispersion and ultrafiltration) (26); (3) available baseline data of SUA levels; (4) determining the effect of baseline SUA on prognosis, with an effect size of $H R$; (5) outcome included cardiovascular or all-cause mortality.

Exclusion criteria: (1) letters, animal studies, reviews, conference reports, meta-analyses; (2) when the same population appeared in different studies, only the one with the longest follow-up period or the most information was included.

SUA levels were used as a categorical variable divided into low, middle, and high levels. The classification of SUA levels was based on the definition in each original study. The lowest uric acid group was defined as low level, the highest uric acid group was

TABLE 2 | Newcastle-Ottawa Scale of included studies.

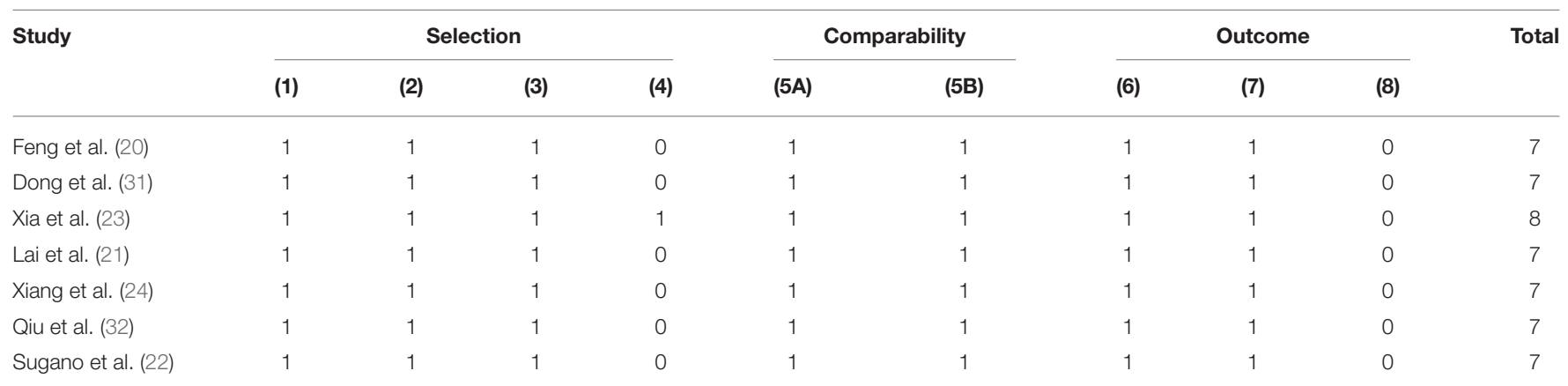

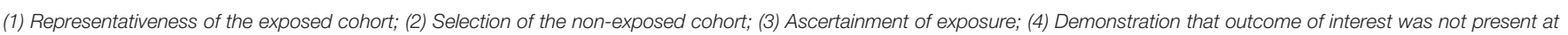

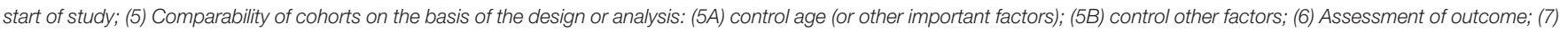
Was follow-up long enough for outcomes to occur; (8) Adequacy of follow up of cohorts. 
A

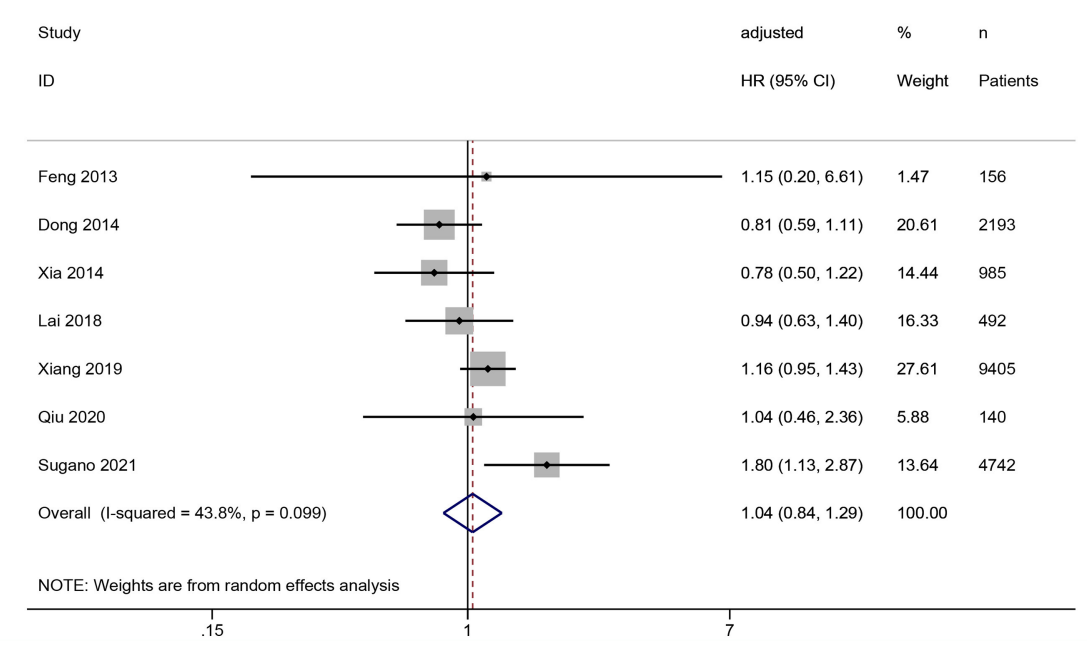

B

Study

ID

adjusted $\quad \%$

HR $(95 \% \mathrm{Cl}) \quad$ Weight Patients

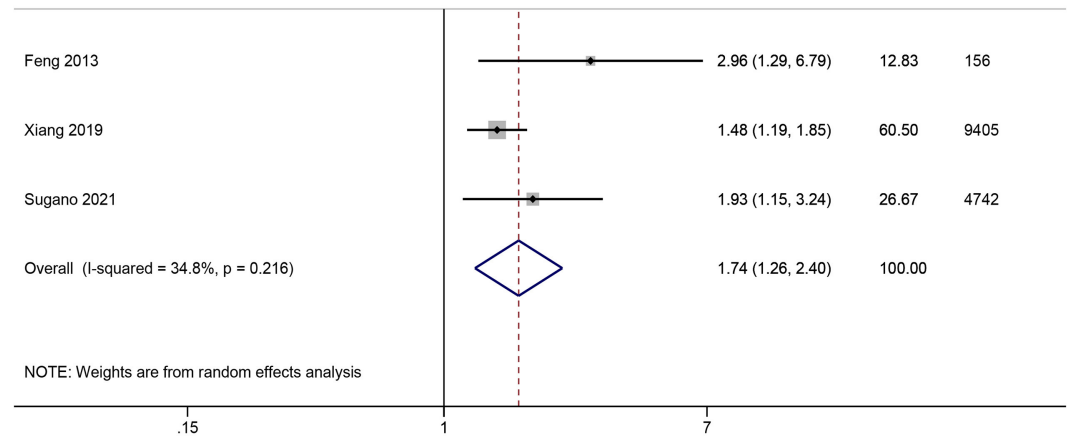

C

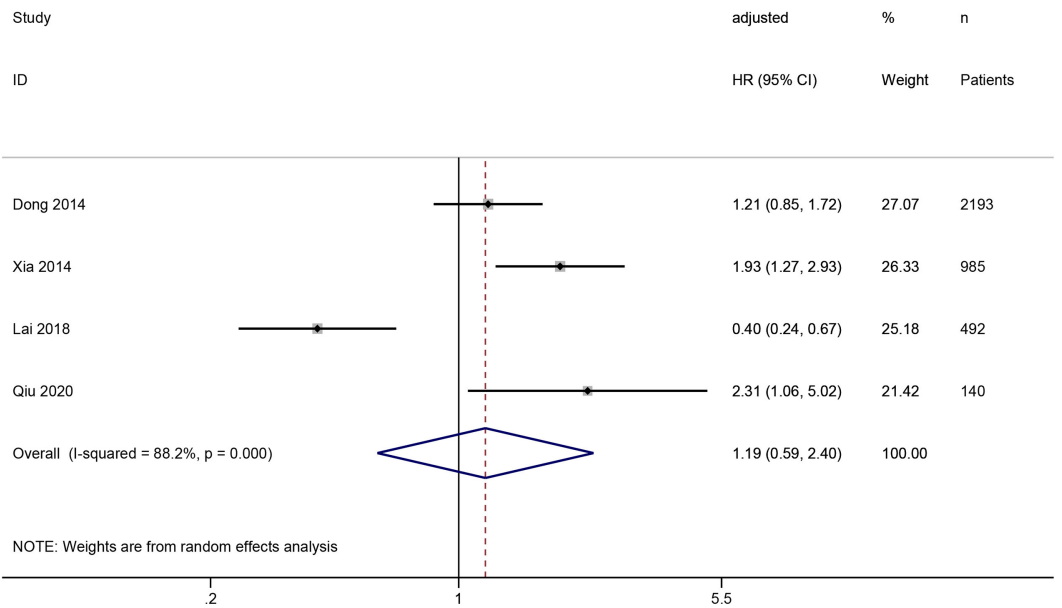

FIGURE 2 | Forest plot of the association between serum uric acid levels and all-cause mortality in PD patients. (A) low vs. middle; (B) high vs. middle; (C) high vs. low. 
defined as high level, and the middle uric acid group was defined as middle level.

\section{Data Extraction}

Two reviewers independently screened each record and extracted data from eligible studies, and any discrepancies were resolved by a comprehensive discussion and reviewed by a third investigator. Extraction of information included the first author, publication year, country, sample size, age, male proportion, the proportions of hypertension and diabetes, baseline uric acid, follow-up period, all-cause and cardiovascular death, comparison, adjusted $H R$ and 95\%CI (the most fully adjusted), and adjusted factors.

\section{Quality Assessment}

The Newcastle-Ottawa Scale (NOS) criteria for cohort studies were used to assess the quality of each included study. The following eight items were evaluated: (1) representativeness of the exposed cohort; (2) selection of the non-exposed cohort; (3) ascertainment of exposure; (4) demonstration that outcome of interest was not present at start of study; (5) comparability of cohorts on the basis of the design or analysis; (6) assessment of outcome; (7) was follow-up long enough for outcomes to occur; (8) adequacy of follow up of cohorts. Selection, comparability, and outcome are three aspects of the NOS criteria. Nine points are the highest score, and the overall quality scores can be divided into good (7-9 points), average (4-6 points), and poor (0-3 points).

The rating of the overall quality of the evidence was undertaken using the Grades of Recommendation, Assessment, Development, and Evaluation (GRADE) approach applied to prognostic studies (27).

The appraisals were processed independently by two reviewers, and the final results were obtained by consensus.

\section{Statistical Analysis}

We used Stata 15.0 (Stata Corp, College Station, TX, USA) for statistical analysis, and all tests were two-tailed. We calculated the significance of the pooled $H R$ by $Z$-test, and $P<0.05$ was considered statistically significant. We used the $Q$-test, $I^{2}$ statistics, and Tau-squared $\left(\tau^{2}\right)$ to judge the magnitude of heterogeneity among studies. We applied the random-effects model to calculate pooled $H R$ and further used the metaregression to explore the sources of heterogeneity. Subgroup analyses were performed by male proportion, sample size, hypertension proportion, and diabetes mellitus proportion. Sensitivity analyses were conducted by omitting each study to assess the robustness of the pooled results. The potential publication bias was qualitatively evaluated by funnel plots and further quantitatively evaluated by Begg's test (28) and Egger's test (29). If publication bias was present, results were adjusted using the trim and fill method (30).

\section{RESULTS}

\section{Summary of the Included Studies}

Two thousand six hundred forty-four and 6 records were originally identified through databases and registers searching. After removing duplicates, 1,713 records were further reviewed. Based on the eligibility criteria, 1,700 records were excluded after screening titles and abstracts, 13 full-text articles were further assessed for eligibility, 6 articles were excluded with reasons. Finally, 7 eligible studies were included in the meta-analysis (20$24,31,32)$, including 7 for all-cause mortality $(20-24,31,32)$ and 4 for cardiovascular mortality $(21,23,24,31)$ (Figure 1).

The included studies encompassed 18,113 patients with allcause mortality data and 13,075 patients with cardiovascular mortality data. All seven studies reported sample size, mean age, baseline SUA, and follow-up period. The sample size of studies ranged from 140 to 9,405 . The proportion of males, hypertension, and diabetes ranged from 45 to $63 \%, 65.7$ to $94.3 \%$, and 12.2 to $37.9 \%$, respectively. All studies provided adjusted $H R(95 \% C I)$ and adjusted factors (Table $\mathbf{1}$ ).

\section{Quality Assessment}

All original studies included in this meta-analysis were cohort study designs, and their quality was assessed according to the NOS criteria. All studies were evaluated seven scores or above and rated as good. The details of the NOS scores were summarized in Table 2.
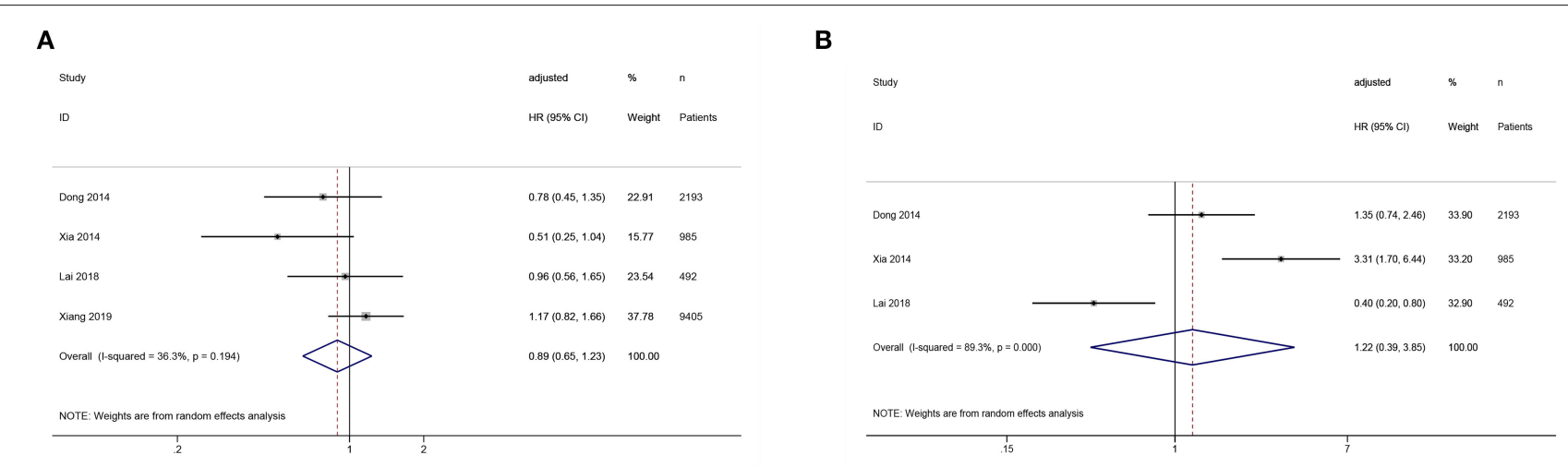

FIGURE 3 | Forest plot of the association between serum uric acid levels and cardiovascular mortality in PD patients. (A) low vs. middle; (B) high vs. low. 
A

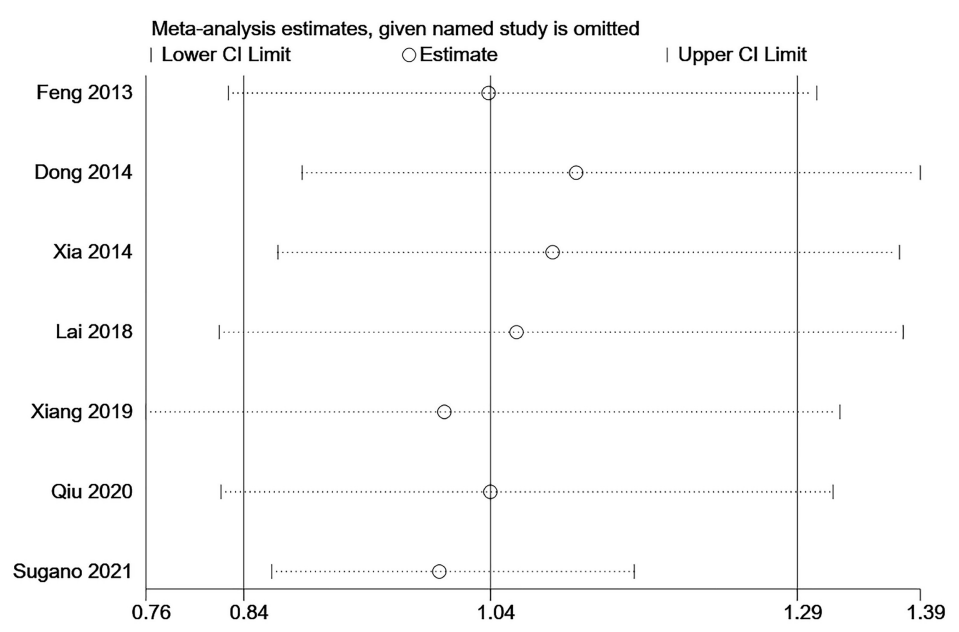

B

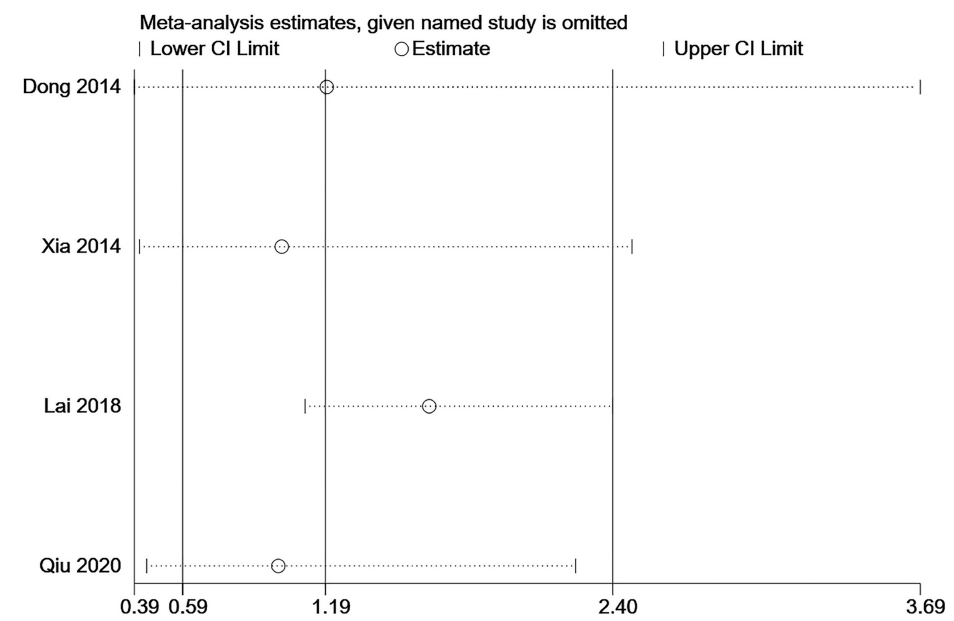

C

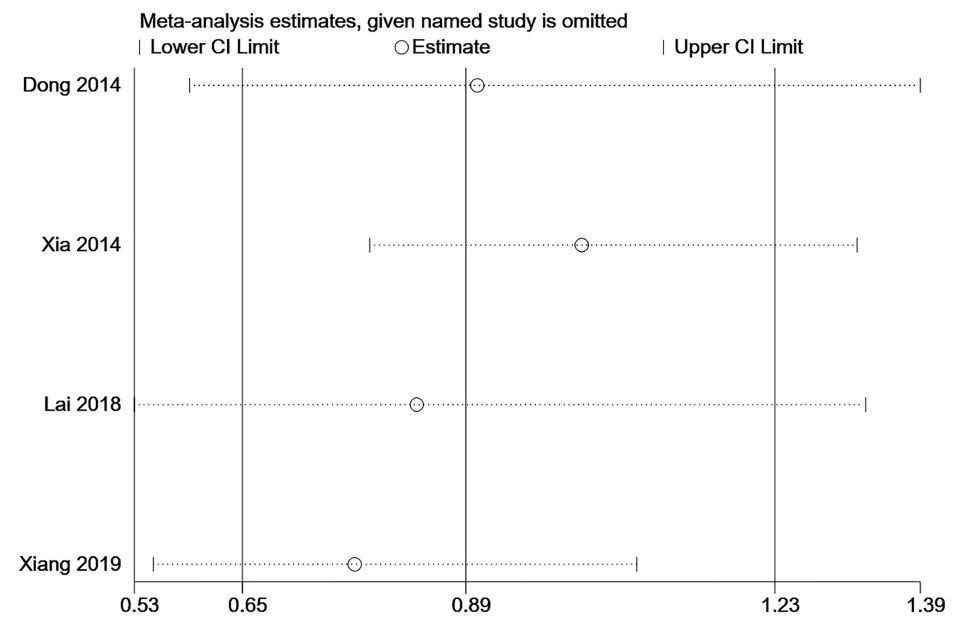

FIGURE 4 | Sensitivity analysis of the association between serum uric acid levels and mortality in PD patients. (A) comparison: low vs. middle, outcome: all-cause mortality; (B) comparison: high vs. low, outcome: all-cause mortality; (C) comparison: low vs. middle, outcome: cardiovascular mortality. 


\section{Serum Uric Acid Levels and All-Cause Mortality}

All seven studies reported the association between SUA levels and all-cause mortality in PD patients. The pooled results showed that compared with middle SUA levels, low SUA levels were not statistically significant in the increased risk of allcause mortality $\left(H R=1.04,95 \% C I: 0.84-1.29, I^{2}=43.8 \%\right.$, $\tau^{2}=0.03$, but the high SUA levels increased the risk of allcause mortality $\left(H R=1.74,95 \% C I: 1.26-2.40, I^{2}=34.8 \%\right.$, $\left.\tau^{2}=0.03\right)$. Compared with low SUA levels, high SUA levels were not statistically significant with an increased risk of all-cause mortality $\left(H R=1.19,95 \% C I: 0.59-2.40, I^{2}=88.2 \%, \tau^{2}=0.44\right)$ (Figures 2A-C).

\section{Serum Uric Acid Levels and Cardiovascular Mortality}

Four studies reported the association between SUA levels and cardiovascular mortality in PD patients. Compared with middle SUA levels, low SUA levels were not associated with a statistically significant risk of cardiovascular mortality $(H R=0.89,95 \% C I$ : $\left.0.65-1.23, I^{2}=36.3 \%, \tau^{2}=0.04\right)$. Compared with the low SUA levels, high SUA levels were not statistically associated with an increased risk of cardiovascular mortality $(H R=1.22,95 \% C I$ : $0.39-3.85, I^{2}=89.3 \%, \tau^{2}=0.92$ ) (Figures 3A,B).

\section{Sensitivity Analysis}

Sensitivity analyses of the association between SUA levels (low vs. middle) and all-cause or cardiovascular mortality showed that omitting individual studies had no significant effect on the pooled results, suggesting good stability of the results (Figures $4 \mathrm{~A}, \mathrm{C}$ ). Sensitivity analysis of the association between SUA levels (high vs. low) and all-cause mortality showed that the pooled result was significantly influenced by omitting Lai's study (21), indicating the stability of the result was relatively poor (Figure 4B).

\section{Subgroup Analysis}

We conducted the subgroup analysis of the association between SUA levels (low vs. middle) and all-cause mortality. Subgroup analyses by male proportion ( $50 \%$ as the cut-off value), sample

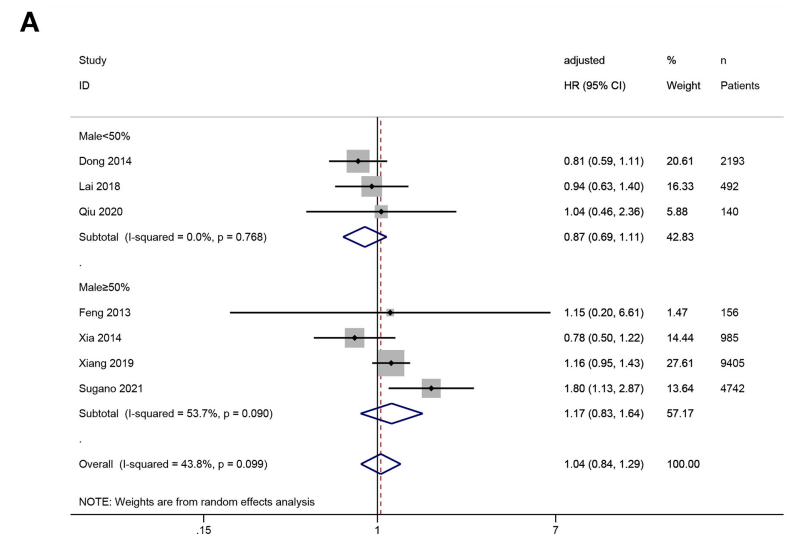

B

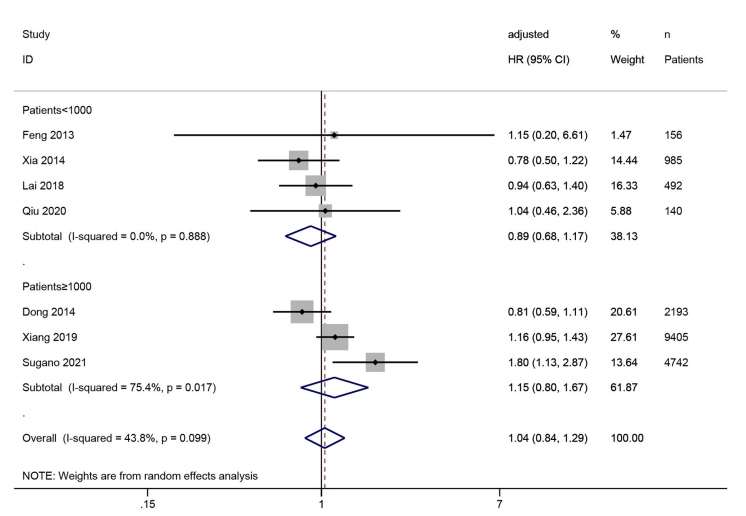

C

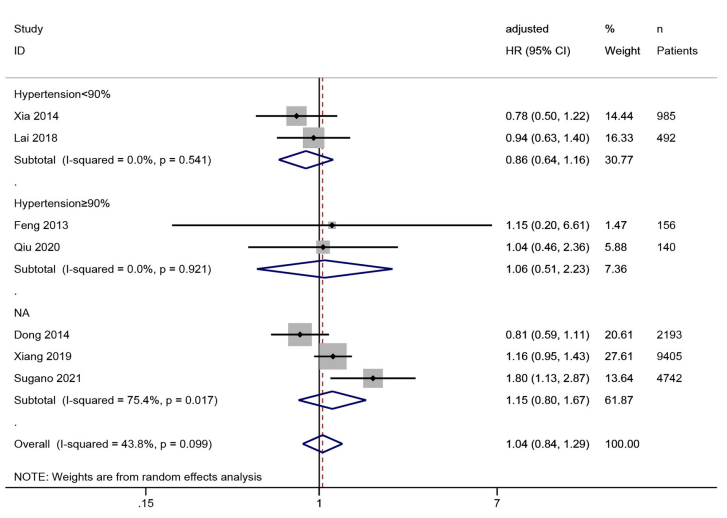

D

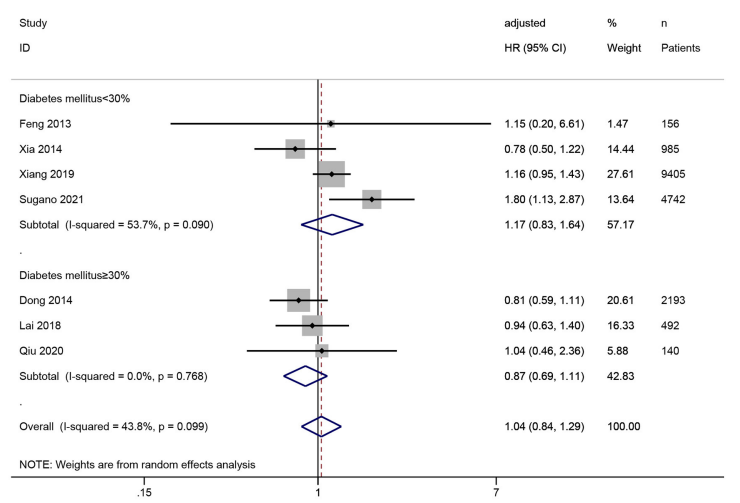

FIGURE 5 | Subgroup analysis of the association between serum uric acid levels (low vs. middle) and all-cause mortality in PD patients. (A) by male proportion (50\% as the cut-off value); (B) by sample size (1,000 as the cut-off value); (C) by hypertension proportion ( $90 \%$ as the cut-off value); (D) by diabetes mellitus proportion (30\% as the cut-off value). 
TABLE 3 | The results of meta-regression analysis.

\begin{tabular}{|c|c|c|c|c|c|c|c|}
\hline \multirow[t]{2}{*}{ Covariates } & \multicolumn{3}{|c|}{ Univariate analysis } & \multicolumn{4}{|c|}{ Multivariate analysis } \\
\hline & $\operatorname{Exp}(b)$ & $95 \% \mathrm{Cl}$ & $P$ & $\operatorname{Exp}(b)$ & $95 \% \mathrm{Cl}$ & $P$ & Adjusted $P$ \\
\hline Male (\%) & 1.31 & $0.75-2.30$ & 0.264 & 1.28 & 0.53-3.09 & 0.442 & 0.703 \\
\hline Sample size & 1.27 & $0.67-2.41$ & 0.381 & 0.55 & $0.01-49.22$ & 0.704 & 0.948 \\
\hline Hypertension (\%) & 1.09 & $0.87-1.37$ & 0.352 & 1.32 & $0.27-6.38$ & 0.613 & 0.863 \\
\hline Diabetes (\%) & 0.76 & $0.43-1.33$ & 0.264 & - & - & - & - \\
\hline
\end{tabular}

Adjusted P was calculated by the Monte Carlo permutation test for meta-regression; Diabetes (\%) was dropped in multivariate analysis because of collinearity.

$\mathrm{Cl}$, confidence interval.

TABLE 4 | Publication bias: Begg's test and Egger's test.

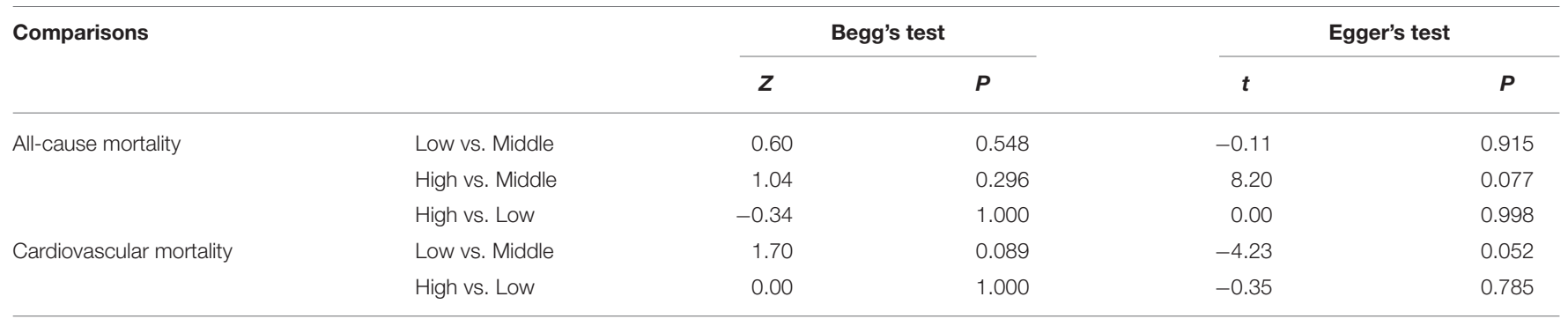

The level behind vs. is the reference group.

size (1,000 as the cut-off value), hypertension proportion $(90 \%$ as the cut-off value), and diabetes mellitus proportion (30\% as the cut-off value) were not statistically significant $(P>0.05)$ (Figures 5A-D).

\section{Meta-Regression Analysis}

We used meta-regression to further explore the potential sources of heterogeneity, including male proportion $(50 \%$ as the cutoff value), sample size (1,000 as the cut-off value), hypertension proportion ( $90 \%$ as the cut-off value), and diabetes mellitus proportion ( $30 \%$ as the cut-off value). Both univariate and multivariate analyses showed that the above factors were not the source of heterogeneity $(P>0.05)$ (Table 3$)$.

\section{Publication Bias}

Neither Begg's test nor Egger's test detected significant publication bias $(P>0.05)$ (Table 4). The shape of the funnel plot (low vs. middle, all-cause mortality) did not show visual evidence of asymmetry (Figure 6).

\section{GRADE Framework for Evidence Quality}

Based on the GRADE approach about prognosis (27), a body of observational evidence begins as high-quality evidence. The quality of evidence was moderate for all-cause mortality (low vs. middle; high vs. middle) and cardiovascular mortality (low vs. middle) due to inconsistency (different cut-off values for SUA classification). The quality of evidence for all-cause mortality (high vs. low) and cardiovascular mortality (high vs. low) was judged to be low due to the inconsistency (different cut-off values for SUA classification) and imprecision (wide 95\% confidence interval) (Table 5).

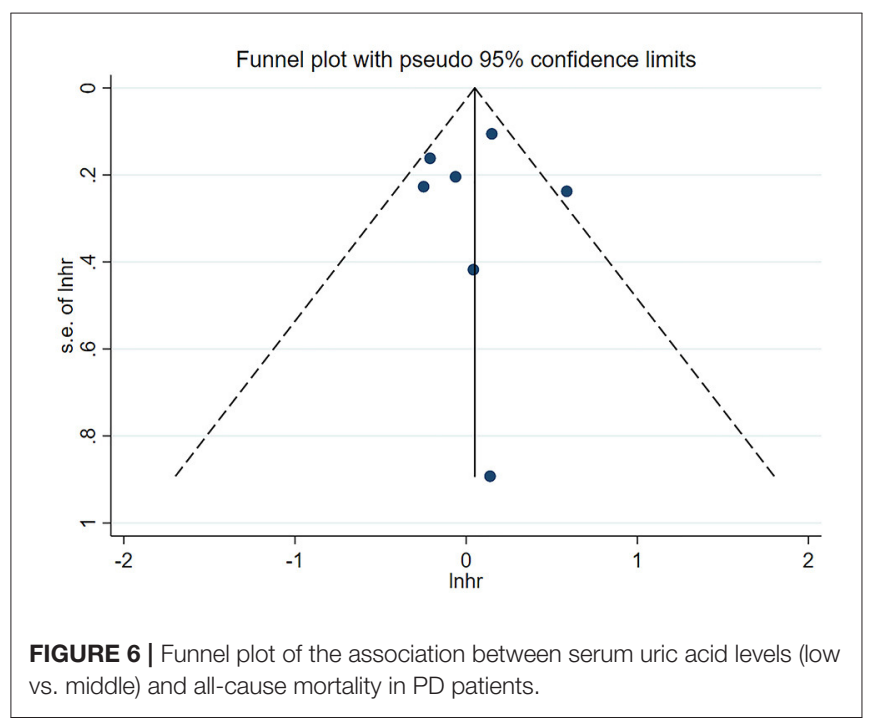

\section{DISCUSSION}

To our knowledge, this is the first meta-analysis of the association between SUA levels and cardiovascular or all-cause mortality in PD patients. The pooled results showed that compared with middle SUA levels, high SUA levels were associated with increased all-cause mortality, while low SUA levels were not significantly associated with all-cause mortality. Besides, SUA levels might not be associated with cardiovascular mortality. The quality of evidence of this meta-analysis was judged to be moderate or low by the GRADE approach, which helps guide 
TABLE 5 | GRADE assessment of the quality of evidence.

\begin{tabular}{|c|c|c|c|c|c|c|c|c|}
\hline Comparisons & & Risk of bias & Indirectness & Inconsistency & Imprecision & Publication bias & Rating up situations ${ }^{a}$ & Quality \\
\hline \multirow[t]{3}{*}{ All-cause mortality } & Low vs. Middle & Not serious ${ }^{b}$ & Not serious $^{\mathrm{C}}$ & Serious $^{d}$ & Not serious ${ }^{e}$ & Not serious ${ }^{f}$ & None & Moderate \\
\hline & High vs. Middle & Not serious ${ }^{b}$ & Not serious ${ }^{\mathrm{C}}$ & Serious $^{d}$ & Not serious ${ }^{e}$ & Not serious $^{f}$ & None & Moderate \\
\hline & High vs. Low & Not serious ${ }^{b}$ & Not serious $^{\mathrm{C}}$ & Serious $^{d}$ & Serious $^{g}$ & Not serious $^{f}$ & None & Low \\
\hline \multirow[t]{2}{*}{ Cardiovascular mortality } & Low vs. Middle & Not serious ${ }^{b}$ & Not serious ${ }^{c}$ & Serious $^{d}$ & Not serious ${ }^{e}$ & Not serious $^{f}$ & None & Moderate \\
\hline & High vs. Low & Not serious ${ }^{\mathrm{b}}$ & Not serious ${ }^{\mathrm{C}}$ & Serious $^{d}$ & Serious $^{\mathrm{g}}$ & Not serious ${ }^{f}$ & None & Low \\
\hline
\end{tabular}

From lorio et al. (27): in the field of prognosis, a body of observational evidence begins as high-quality evidence.

${ }^{a}$ Rating up situations included large effect, dose response gradient, and direction of plausible confounding.

${ }^{b}$ Risk of bias was judged low for individual studies (seven NOS scores or above) (see Table 2).

${ }^{c}$ Appropriate population generalizability and outcomes applicability.

${ }^{d}$ Different cut-off values for SUA classification.

${ }^{e}$ Narrow $95 \%$ confidence interval.

${ }^{f}$ No publication bias detected (see Table 4).

g Wide 95\% confidence interval.

future research and clinical practice. Because current metaanalysis includes a relatively small number of studies, thus more large-sample and high-level studies are needed to determine the association between SUA levels and cardiovascular or all-cause mortality in PD patients. With the publication of relevant studies, this meta-analysis can be further updated in the future.

Our results showed that compared with middle SUA levels, high SUA levels were associated with an increased risk of allcause mortality in PD patients. The possible reasons may be as follows: First, uric acid may induce oxidative stress by activating NADPH oxidase, stimulating the renin-angiotensin system (RAS), and disturbing mitochondrial function (33-35). Second, SUA can regulate inflammatory responses through a variety of cytokines (36). The pathophysiological mechanisms underlying the inflammatory state in CKD are complex and involve maladaptive cellular responses to injury, leading to sustained activation of proinflammatory and profibrotic signals $(37,38)$. Mouse models of CKD suggest that uric acid contributes to the pathophysiological processes described above. In the remnant kidney model, hyperuricemic rats exhibited higher blood pressure and proteinuria levels than normouricemic rats, which were histologically associated with greater glomerulosclerosis, interstitial fibrosis, and vascular lesions (39, 40). Third, hyperuricemia is associated with endothelial dysfunction. Uptake of uric acid into endothelial cells causes inflammation, oxidative stress, and eNOS dephosphorylation, leading to endothelial dysfunction by reducing NO bioavailability (41). Finally, high uric acid levels may reduce residual renal function in PD patients, leading to increased all-cause mortality $(42,43)$.

The pooled results indicated no significant association between SUA levels and cardiovascular mortality in PD patients, which might be due to the dual effects of SUA on the cardiovascular system. On the one hand, redundant SUA can cause inflammation, oxidative stress, endothelial dysfunction, and activation of the renin-angiotensin system, leading to cardiovascular disease $(33-36,41-45)$. On the other hand, many experiments have shown that uric acid is a potent free radical scavenger beneficial to the cardiovascular system $(46,47)$. Therefore, the association between SUA levels and cardiovascular mortality in $\mathrm{PD}$ patients may be balanced between protective and toxic effects. However, because only four related studies are included in this meta-analysis, and the individual study results are different, which may induce heterogeneity. Hence, the association between SUA levels and cardiovascular mortality in PD patients needs more high-level studies to validate.

Sensitivity analysis showed that compared with low SUA levels, high SUA levels were associated with an increased risk of all-cause mortality after excluding Lai's study (21). The results of Lai's study were significantly different from others, possibly because Lai's study had a longer median follow-up period ( $>3$ years), while uric acid might have a more remarkable ability to predict mortality in PD patients within 3 years (32). Based on Lai's findings, the beneficial effect of UA on all-cause mortality seems to outweigh its harmful effect, and thus may have a protective effect in PD patients. This may be explained by the association between low SUA levels and malnutrition and may increase oxidative stress. Besides, different studies adjust for different confounders, the residual confounding bias may remain, which may contribute to the heterogeneity of results.

This meta-analysis has the following limitations: First, all the included studies were cohort studies, the potential confounders could not be adjusted entirely. Second, heterogeneity was observed among the included studies. Each study was adjusted for inconsistent confounding factors, with different cut-off values for SUA classification. Third, as a result of the limited number of relevant studies published, the number of studies included in this meta-analysis was insufficient and led to inadequate power to conduct subgroup and meta-regression analysis. Fourth, only few of the included studies reported SUA as a continuous variable and had different units, so we only considered SUA as a categorical variable.

\section{CONCLUSION}

In conclusion, compared with middle SUA levels, high SUA levels are associated with an increased risk of all-cause mortality in PD patients. SUA levels may not be associated with cardiovascular mortality. More high-level studies, especially randomized controlled trials, are needed to determine the 
association between SUA levels and cardiovascular or all-cause mortality in PD patients.

\section{DATA AVAILABILITY STATEMENT}

Publicly available datasets were analyzed in this study. This data can be found at: PubMed, Embase, Web of Science, the Cochrane Library, CNKI, VIP, and Wanfang databases.

\section{AUTHOR CONTRIBUTIONS}

Z-qL, Z-wH, S-lK, FY, and Z-jH designed the study and drafted the manuscript. Z-qL, Z-wH, and S-lK extracted the data and

\section{REFERENCES}

1. Hill NR, Fatoba ST, Oke JL, Hirst JA, O'Callaghan CA, Lasserson DS, et al. Global prevalence of chronic kidney disease - a systematic review and metaanalysis. PLoS One. (2016) 11:e0158765. doi: 10.1371/journal.pone.0158765

2. GBD Chronic Kidney Disease Collaboration. Global, regional, and national burden of chronic kidney disease, 1990-2017: a systematic analysis for the Global Burden of Disease Study 2017. Lancet. (2020) 395:709-33. doi: 10.1016/s0140-6736(20)30045-3

3. Hole B, Hemmelgarn B, Brown E, Brown M, McCulloch MI, Zuniga C, et al. Supportive care for end-stage kidney disease: an integral part of kidney services across a range of income settings around the world. Kidney Int Suppl. (2020) 10:e86-94. doi: 10.1016/j.kisu.2019.11.008

4. Liyanage T, Ninomiya T, Jha V, Neal B, Patrice HM, Okpechi I, et al. Worldwide access to treatment for end-stage kidney disease: a systematic review. Lancet. (2015) 385:1975-82. doi: 10.1016/S0140-6736(14)61601-9

5. Bello AK, Levin A, Tonelli M, Okpechi IG, Feehally J, Harris D, et al. Assessment of global kidney health care status. JAMA. (2017) 317:1864-81. doi: 10.1001/jama.2017.4046

6. Chaudhary K, Sangha H, Khanna R. Peritoneal dialysis first: rationale. Clin J Am Soc Nephrol. (2011) 6:447-56. doi: 10.2215/CJN.07920910

7. Heaf JG, Wehberg S. Relative survival of peritoneal dialysis and haemodialysis patients: effect of cohort and mode of dialysis initiation. PLoS One. (2014) 9:e90119. doi: 10.1371/journal.pone.0090119

8. Lukowsky LR, Mehrotra R, Kheifets L, Arah OA, Nissenson AR, KalantarZadeh K. Comparing mortality of peritoneal and hemodialysis patients in the first 2 years of dialysis therapy: a marginal structural model analysis. Clin J Am Soc Nephrol. (2013) 8:619-28. doi: 10.2215/CJN.04810512

9. Yeates K, Zhu N, Vonesh E, Trpeski L, Blake P, Fenton S. Hemodialysis and peritoneal dialysis are associated with similar outcomes for end-stage renal disease treatment in Canada. Nephrol Dial Transplant. (2012) 27:3568-75. doi: $10.1093 / \mathrm{ndt} / \mathrm{gfr} 674$

10. Tedeschi A, Agostoni P, Pezzuto B, Corra U, Scrutinio D, La Gioia R, et al. Role of comorbidities in heart failure prognosis Part 2: chronic kidney disease, elevated serum uric acid. Eur J Prev Cardiol. (2020) 27:35-45. doi: $10.1177 / 2047487320957793$

11. Maiuolo J, Oppedisano F, Gratteri S, Muscoli C, Mollace V. Regulation of uric acid metabolism and excretion. Int J Cardiol. (2016) 213:8-14. doi: 10.1016/j.ijcard.2015.08.109

12. Johnson RJ, Bakris GL, Borghi C, Chonchol MB, Feldman D, Lanaspa MA, et al. Hyperuricemia, acute and chronic kidney disease, hypertension, and cardiovascular disease: report of a scientific workshop organized by the national kidney foundation. Am J Kidney Dis. (2018) 71:851-65. doi: 10.1053/j.ajkd.2017.12.009

13. Wang J, Qin T, Chen J, Li Y, Wang L, Huang H, et al. Hyperuricemia and risk of incident hypertension: a systematic review and meta-analysis of observational studies. PLoS One. (2014) 9:e114259. doi: 10.1371/journal.pone.0114259 evaluated the quality. C-cH, FC, and FH verified the data. $\mathrm{Z}-\mathrm{qL}$, $\mathrm{Z}$-wH, and ZL analyzed the data. Z-qL, S-1K, FY, and Z-jH revised the manuscript. Z-qL, ZL, FY, and Z-jH interpreted the results. $\mathrm{Z}-\mathrm{qL}, \mathrm{Z}-\mathrm{jH}, \mathrm{C}-\mathrm{cH}, \mathrm{FC}$, and FH incorporated comments for the co-authors and finalized the manuscript. All authors approved the final version of the paper.

\section{FUNDING}

This study was supported by the key Clinical Specialty Discipline Construction Program of Fuzhou, Fujian, P.R.C, the Startup Fund for scientific research, Fujian Medical University (Grant number: 2019QH1297), and the Scientific Foundation of Fuzhou City (Grant number: 2020-WS-57).

14. Li J, Huang JY, Liu L, Lo K, Sun S, Chen CL, et al. Relationship between serum uric acid level and all-cause and cardiovascular mortality in population with obesity. Postgrad Med J. (2020) 96:660-5. doi: 10.1136/postgradmedj-2019-137236

15. Stubnova V, Os I, Høieggen A, Solbu MD, Grundtvig M, Westheim AS, et al. Gender differences in association between uric acid and all-cause mortality in patients with chronic heart failure. BMC Cardiovasc Disord. (2019) 19:4. doi: 10.1186/s12872-018-0989-8

16. Jalal DI, Chonchol M, Chen W, Targher G. Uric acid as a target of therapy in CKD. Am J Kidney Dis. (2013) 61:134-46. doi: 10.1053/j.ajkd.2012.07.021

17. Zhang J, Lu X, Li H, Wang S. Serum uric acid and mortality in patients with chronic kidney disease: a systematic review and meta-analysis. Blood Purif. (2021) 50:758-66. doi: 10.1159/000513944

18. Luo Q, Xia X, Li B, Lin Z, Yu X, Huang F. Serum uric acid and cardiovascular mortality in chronic kidney disease: a meta-analysis. BMC Nephrol. (2019) 20:18. doi: 10.1186/s12882-018-1143-7

19. Wang H, Liu J, Xie D, Liu H, Zhen L, Guo D, et al. Elevated serum uric acid and risk of cardiovascular or all-cause mortality in maintenance hemodialysis patients: a meta-analysis. Nutr Metab Cardiovasc Dis. (2021) 31:372-81. doi: 10.1016/j.numecd.2020.11.017

20. Feng S, Jiang L, Shi Y, Shen H, Shi X, Jin D, et al. Uric acid levels and allcause mortality in peritoneal dialysis patients. Kidney Blood Press Res. (2013) 37:181-9. doi: 10.1159/000350143

21. Lai KJ, Kor CT, Hsieh YP. An inverse relationship between hyperuricemia and mortality in patients undergoing continuous ambulatory peritoneal dialysis. J Clin Med. (2018) 7:416. doi: 10.3390/jcm7110416

22. Sugano N, Maruyama Y, Ohno I, Wada A, Shigematsu T, Masakane I, et al. Effect of uric acid levels on mortality in Japanese peritoneal dialysis patients. Perit Dial Int. (2021) 41:320-7. doi: 10.1177/08968608209 29476

23. Xia X, He F, Wu X, Peng F, Huang F, Yu X. Relationship between serum uric acid and all-cause and cardiovascular mortality in patients treated with peritoneal dialysis. Am J Kidney Dis. (2014) 64:257-64. doi: 10.1053/j.ajkd.2013.08.027

24. Xiang S, Zhang X, Xie X, Wang J, Zhou Q, Chen Z, et al. High serum uric acid level is a mortality risk factor in peritoneal dialysis patients: a retrospective cohort study. Nutr Metab. (2019) 16:52. doi: 10.1186/s12986-019-0379-y

25. Page MJ, McKenzie JE, Bossuyt PM, Boutron I, Hoffmann TC, Mulrow CD, et al. The PRISMA 2020 statement: an updated guideline for reporting systematic reviews. BMJ. (2021) 372:n71. doi: 10.1136/bmj.n71

26. Liu L, Zhang L, Liu GJ, Fu P. Peritoneal dialysis for acute kidney injury. Cochrane Database Syst Rev. (2017) 12:Cd011457. doi: 10.1002/14651858.CD011457.pub2

27. Iorio A, Spencer FA, Falavigna M, Alba C, Lang E, Burnand B, et al. Use of GRADE for assessment of evidence about prognosis: rating confidence in estimates of event rates in broad categories of patients. BMJ. (2015) 350:h870. doi: 10.1136/bmj.h870 
28. Begg CB, Mazumdar M. Operating characteristics of a rank correlation test for publication bias. Biometrics. (1994) 50:1088-101. doi: 10.2307/2533446

29. Egger M, Davey Smith G, Schneider M, Minder C. Bias in metaanalysis detected by a simple, graphical test. BMJ. (1997) 315:629-34. doi: 10.1136/bmj.315.7109.629

30. Duval S, Tweedie R. Trim and fill: a simple funnel-plot-based method of testing and adjusting for publication bias in meta-analysis. Biometrics. (2000) 56:455-63. doi: 10.1111/j.0006-341X.2000.00455.x

31. Dong J, Han QF, Zhu TY, Ren YP, Chen JH, Zhao HP, et al. The associations of uric acid, cardiovascular and all-cause mortality in peritoneal dialysis patients. PLoS One. (2014) 9:e82342. doi: 10.1371/journal.pone.0082342

32. Qiu S, Teng J, Shen B, Pei J, Cai Q, Zhang Y. Correlation of serum uric acid before dialysis and all-cause mortality in peritoneal dialysis patients. Chinese J Clin Med. (2020) 27:815-21. doi: 10.12025/j.issn.1008-6358.2020.20192078

33. Sanchez-Lozada LG, Andres-Hernando A, Garcia-Arroyo FE, Cicerchi $\mathrm{C}, \mathrm{Li} \mathrm{N}$, Kuwabara $\mathrm{M}$, et al. Uric acid activates aldose reductase and the polyol pathway for endogenous fructose and fat production causing development of fatty liver in rats. J Biol Chem. (2019) 294:4272-81. doi: $10.1074 /$ jbc.RA118.006158

34. Corry DB, Eslami P, Yamamoto K, Nyby MD, Makino H, Tuck ML. Uric acid stimulates vascular smooth muscle cell proliferation and oxidative stress via the vascular renin-angiotensin system. J Hypertens. (2008) 26:269-75. doi: 10.1097/HJH.0b013e3282f240bf

35. Kim SM, Lee SH, Kim YG, Kim SY, Seo JW, Choi YW, et al. Hyperuricemiainduced NLRP3 activation of macrophages contributes to the progression of diabetic nephropathy. Am J Physiol Renal Physiol. (2015) 308:F993-1003. doi: 10.1152/ajprenal.00637.2014

36. Xiao J, Zhang XL, Fu C, Han R, Chen W, Lu Y, et al. Soluble uric acid increases NALP3 inflammasome and interleukin- $1 \beta$ expression in human primary renal proximal tubule epithelial cells through the Toll-like receptor 4-mediated pathway. Int J Mol Med. (2015) 35:1347-54. doi: 10.3892/ijmm.2015.2148

37. Chawla LS, Eggers PW, Star RA, Kimmel PL. Acute kidney injury and chronic kidney disease as interconnected syndromes. N Engl J Med. (2014) 371:58-66. doi: 10.1056/NEJMra1214243

38. Strausser SA, Nakano D, Souma T. Acute kidney injury to chronic kidney disease transition: insufficient cellular stress response. Curr Opin Nephrol Hypertens. (2018) 27:314-22. doi: 10.1097/MNH.0000000000000424

39. Kang DH, Nakagawa T, Feng L, Watanabe S, Han L, Mazzali M, et al. A role for uric acid in the progression of renal disease. J Am Soc Nephrol. (2002) 13:2888-97. doi: 10.1097/01.ASN.0000034910.58454.FD

40. Sánchez-Lozada LG, Tapia E, Santamaría J, Avila-Casado C, Soto V, Nepomuceno T, et al. Mild hyperuricemia induces vasoconstriction and maintains glomerular hypertension in normal and remnant kidney rats. Kidney Int. (2005) 67:237-47. doi: 10.1111/j.1523-1755.2005.00074.x
41. Maruhashi T, Hisatome I, Kihara Y, Higashi Y. Hyperuricemia and endothelial function: from molecular background to clinical perspectives. Atherosclerosis. (2018) 278:226-31. doi: 10.1016/j.atherosclerosis.2018. 10.007

42. Hsieh YP, Yang Y, Chang CC, Kor CT, Wen YK, Chiu PF, et al. Ushaped relationship between uric acid and residual renal function decline in continuous ambulatory peritoneal dialysis patients. Nephrology. (2017) 22:427-35. doi: 10.1111/nep.12613

43. Yang C, Ma X, Zhao W, Chen Y, Lin H, Luo D, et al. A longitudinal analysis of the relationship between serum uric acid and residual renal function loss in peritoneal dialysis patients. Ren Fail. (2020) 42:447-54. doi: 10.1080/0886022X.2020.1761387

44. Braga TT, Forni MF, Correa-Costa M, Ramos RN, Barbuto JA, Branco P, et al. Soluble uric acid activates the NLRP3 inflammasome. Sci Rep. (2017) 7:39884. doi: $10.1038 /$ srep39884

45. Mishima M, Hamada $T$, Maharani N, Ikeda N, Onohara $T$, Notsu $T$, et al. Effects of uric acid on the NO production of HUVECs and its restoration by urate lowering agents. Drug Res. (2016) 66:270-4. doi: 10.1055/ s-0035-1569405

46. Nieto FJ, Iribarren C, Gross MD, Comstock GW, Cutler RG. Uric acid and serum antioxidant capacity: a reaction to atherosclerosis? Atherosclerosis. (2000) 148:131-9. doi: 10.1016/S0021-9150(99)00214-2

47. Suzuki T. Nitrosation of uric acid induced by nitric oxide under aerobic conditions. Nitric Oxide. (2007) 16:266-73. doi: 10.1016/j.niox.2006. 10.008

Conflict of Interest: The authors declare that the research was conducted in the absence of any commercial or financial relationships that could be construed as a potential conflict of interest.

Publisher's Note: All claims expressed in this article are solely those of the authors and do not necessarily represent those of their affiliated organizations, or those of the publisher, the editors and the reviewers. Any product that may be evaluated in this article, or claim that may be made by its manufacturer, is not guaranteed or endorsed by the publisher.

Copyright (c) 2021 Liu, Huang, Kang, Hu, Chen, He, Lin, Yang and Hu. This is an open-access article distributed under the terms of the Creative Commons Attribution License (CC BY). The use, distribution or reproduction in other forums is permitted, provided the original author(s) and the copyright owner(s) are credited and that the original publication in this journal is cited, in accordance with accepted academic practice. No use, distribution or reproduction is permitted which does not comply with these terms. 